This article has been published in Additive Manufacturing. The final publication is available at Elsevier via https://doi.org/10.1016/j.addma.2018.04.006

\title{
Additive manufacturing of a novel Ti-Al-V-Fe alloy using Selective Laser Melting
}

Hamid Azizi ${ }^{1}$,Hatem Zurob ${ }^{1}$, Bipasha Bose ${ }^{2}$, S. Reza Ghiaasiaan ${ }^{1}$, Xiang Wang ${ }^{1}$, Simon

$$
\text { Coulson }{ }^{3} \text {,Vlad Duz }{ }^{4} \text {, A.B. Phillion }{ }^{{ }^{*}}
$$

${ }^{1}$ Department of Materials Science and Engineering, McMaster University, Hamilton, Ontario, L8S 4L7, Canada

${ }^{2}$ Department of Mechanical Engineering, McMaster University, Hamilton, Ontario, L8S 4L7, Canada

${ }^{3}$ Additive Manufacturing Innovation Centre, Mohawk College, Hamilton, Ontario, L9C 0E5, Canada

${ }^{4}$ ADMA Advanced Materials Products, Inc., Hudson, Ohio, USA

*Corresponding Author: andre.phillion@mcmaster.ca

Abstract: Ti-1Al-8V-5Fe (Ti-185) and other Fe containing $\beta$-Ti alloys are attractive because of their high strength and low cost. These alloys, however, cannot be produced through ingot casting due to strong Fe segregation and the formation of $\beta$ flecks. Selective Laser Melting (SLM) was successfully used to produce Ti-185 components starting from elemental Ti and Fe powders, and an Al-V master alloy powder with irregular shape. Microstructure analysis of the as-built components demonstrated that SLM can be used to produce a very fine grain microstructure with nano-scale precipitates and non-detrimental $\mathrm{Fe}$ segregation. The findings are interpreted in terms of the rapid solidification conditions during SLM. Compression test results reveal that ultra-high strength and reasonable ductility can be achieved in the as-built as well as heat treated samples.

Keywords: Rapid solidification, Selective laser melting, Powder processing, Titanium alloys,

\section{Solidification microstructure}

\section{Introduction}

Additive manufacturing (AM) is an emerging technology for producing near-net-shaped components directly from powders or wires melted by a high-power-density heat source. The main advantage of AM is its ability to directly produce complex geometries with minimal material waste. New material options are required that take advantage of the corresponding rapid solidification rates.

Titanium alloys provide components with high specific strength and high operating temperatures. In recent years, (near) $\beta$-Ti alloys have been widely explored owing to their higher strength, and improved combinations of toughness and fatigue resistance as compared to other $\mathrm{Ti}$ alloys [1]. These alloys contain high additions of $\beta$ stabilizing elements (Mo, $\mathrm{V}, \mathrm{Cr}, \mathrm{Fe}$ ). Wide- 
scale adoption of $\beta$-Ti alloys is limited due to high costs, which are partly due to the cost of the Mo, V, and $\mathrm{Cr}$ alloying elements. Ti-1Al-8V-5Fe (Ti-185) is a unique low-cost $\beta$-Ti alloy, containing lower cost alloying elements, notably Fe, as compared to Ti-10V-2Fe-3Al (Ti-1023) and Ti-5Al-5V-5Mo-3Cr (Ti-5553) while offering high strength and fatigue life. Although Ti-185 was patented more than 50 years ago, it is not commercially viable using traditional processing. This is because strong micro-segregation of Fe occurs during casting [2,3], resulting in large variations in composition and leading to the precipitation of brittle phases. For the few niche applications where Ti-185 is currently utilized, the alloy is heat-treated to produce a microstructure consisting of a $\beta$ matrix with primary $\alpha$ phases at the grain boundaries as well as a nano-scale distribution of $\alpha$ precipitates within the grain interiors.

Recently, Joshi et al. [4] developed a processing route for Ti-185 consisting of powder metallurgy followed by thermo-mechanical processing. In this way, both the segregation of Fe and the formation of detrimental $\beta$ fleck phase were bypassed. $(\beta$ flecks are $\beta$ phase regions strongly enriched with $\beta$ stabilizing elements such as Fe and/or $\mathrm{Cr}$ [5]). Although the properties were excellent (1655 MPa strength and 4-6\% elongation), a lengthy and costly sintering treatment and multiple rolling steps were required for component fabrication [6]. Using an aging treatment below the $\beta$-transus temperature, Devaraj et al. [6] then developed a hierarchical nano-structured alloy with very fine primary and secondary $\alpha$ within the $\beta$-matrix. This microstructure resulted in a unique combination of strength and ductility, surpassing available commercial Ti alloys.

In the present, the use of Ti-185 as a novel material for Selective Laser Melting (SLM) (a powder-bed based AM technology) is investigated. Compared to the $\alpha+\beta$ grades, very few studies on AM of $\beta$ titanium alloys have been published [7,8,9,10,11,12]. This is thought to be due to the limited powder stock available for SLM. The main objective of this work is to develop a printed component of Ti-185 alloy having minimal segregation and porosity, and reasonable mechanical properties. During AM of metals, the cooling rates are estimated to reach up to $10^{3}-10^{4} \mathrm{C} / \mathrm{s}[13]$, which could greatly reduce Fe segregation and minimize the formation of the $\beta$ flecks, ensuring that the optimal component yield strength and toughness is achieved. Eylon and Froes pointed out that Ti-185 should only be used with processes enabling rapid transformation from the liquid to the solid state [14]. It would thus appear that AM, characterized by high solidification rates, is uniquely suited for processing Ti-185. 


\section{Materials and Methods}

Ti-185 powder was obtained from ADMA Advanced Materials Products, Inc., Hudson, Ohio. The powder is an elemental mixture of Ti, Fe, and a V-Al master alloy. First, the powder was ball milled and sieved to achieve the appropriate size distribution for SLM. Ball milling, traditionally used in powder metallurgy, has also been used in recent years to develop elemental powders suitable for AM processes $[15,16]$. The use of elemental powder as feedstock also contributes to material saving costs and allows for future flexibility in alloy design. The powder characteristics (size distribution, flowability and apparent density) were measured using a laser diffraction technique and Hall tests following ASTM standards B212 [17] and B213 [18]. Second, an EOS-M280 SLM apparatus was used to build a series of sample coupons for metallographic examination and mechanical testing. The base plate was a Ti-5553 near- $\beta$ titanium alloy, preheated to $80{ }^{\circ} \mathrm{C}$. A stripe laser pattern was used with the laser power, scanning speed, hatch spacing and layer thickness being $370 \mathrm{~W}, 1035 \mathrm{~mm} / \mathrm{s}, 0.12 \mathrm{~mm}$ and $0.06 \mathrm{~mm}$, respectively. During every new layer, the stripes were rotated counterclockwise by $\sim 67^{\circ}$ compared to the previous layer. This set of parameters was equivalent to a power density of approximately $50.4 \mathrm{~J} / \mathrm{mm}^{3}$, and was used based on values published previously [19]. An argon atmosphere was maintained throughout the build process. Third, samples were cut, ground and polished with a mixture of $10 \%$ hydrogen peroxide in colloidal silica as the last polishing step. Kroll's solution was used to etch the samples. Fourth, optical and electron microscopy were performed, along with electron back-scatter diffraction (EBSD) and energy-dispersive spectroscopy (EDS) for microstructural and chemical analyses. Xray diffraction (XRD) was also carried out in order to identify the phases present in both the powder and the as-built samples. Finally, compression tests were performed on cylindrical samples $5 \mathrm{~mm}$ in diameter and $8 \mathrm{~mm}$ height using a universal MTS machine at nominal strain rate of $1 \times 10^{-3} \mathrm{~s}^{-1}$. Teflon tape was used as a lubricant between the samples and the platens. 


\section{Results and Discussion}

\subsection{Initial powder characterization}

Figure 1 presents an overview of the Ti-185 powder characteristics. Figure 1a shows the backscatter electron image of the Ti-185 elemental powder. As can be seen, the powder has irregular shape as a result of being fabricated using ball milling. The XRD results show the three main constituents of the powder as titanium, a vanadium-aluminum master alloy and iron particles. The powder has a relatively wide size distribution with the particle diameters at $10 \%, 50 \%$ and $90 \%$ in the cumulative distribution being 21,51 , and $68 \mu \mathrm{m}$, respectively. The Hall flowability test indicates that the powder had no flowability, and an apparent density of $3.1 \mathrm{~g} / \mathrm{cm}^{3}$.

\subsection{Characterization of the as-built structure}

Figures $2 \mathrm{a}$ and $2 \mathrm{~b}$ show optical micrographs of the SLM-built sample in the as-polished and etched conditions. The individual build layers are visible, along with a small amount of porosity. Using image analysis techniques, the average porosity content was evaluated to be $\sim 0.62 \%$, which is much lower than typical powder processing techniques. Using the Archimedes method, the density of the as-built structure was measured to be $4.6618 \mathrm{~g} / \mathrm{cm}^{3}$ which is very close to the theoretical density of this alloy, i.e. $4.6676 \mathrm{~g} / \mathrm{cm}^{3}$. Figure 2c shows an XRD map of the Ti-185 as-built sample shown in Figure $2 \mathrm{~b}$, confirming the presence of both the body centered cubic $\beta$ phase and the hexagonal close-packed $\alpha$ phase. A corresponding EDS line scan of $\sim 300 \mu \mathrm{m}$ and equivalent to 5 deposition layers, Figure 2d, showed no macroscale gradients in any of the alloying elements. This is consistent with solidification occurring only at the scale of the powder layer. The average oxygen content of the as-built sample was determined via EDS to be $\sim 0.78$ wt.\%. Note that a second XRD pattern, a Ti-185 sample subsequently heated to $1200^{\circ} \mathrm{C}$, is also shown in Figure $2 \mathrm{c}$. This will be discussed as part of Figure 5 

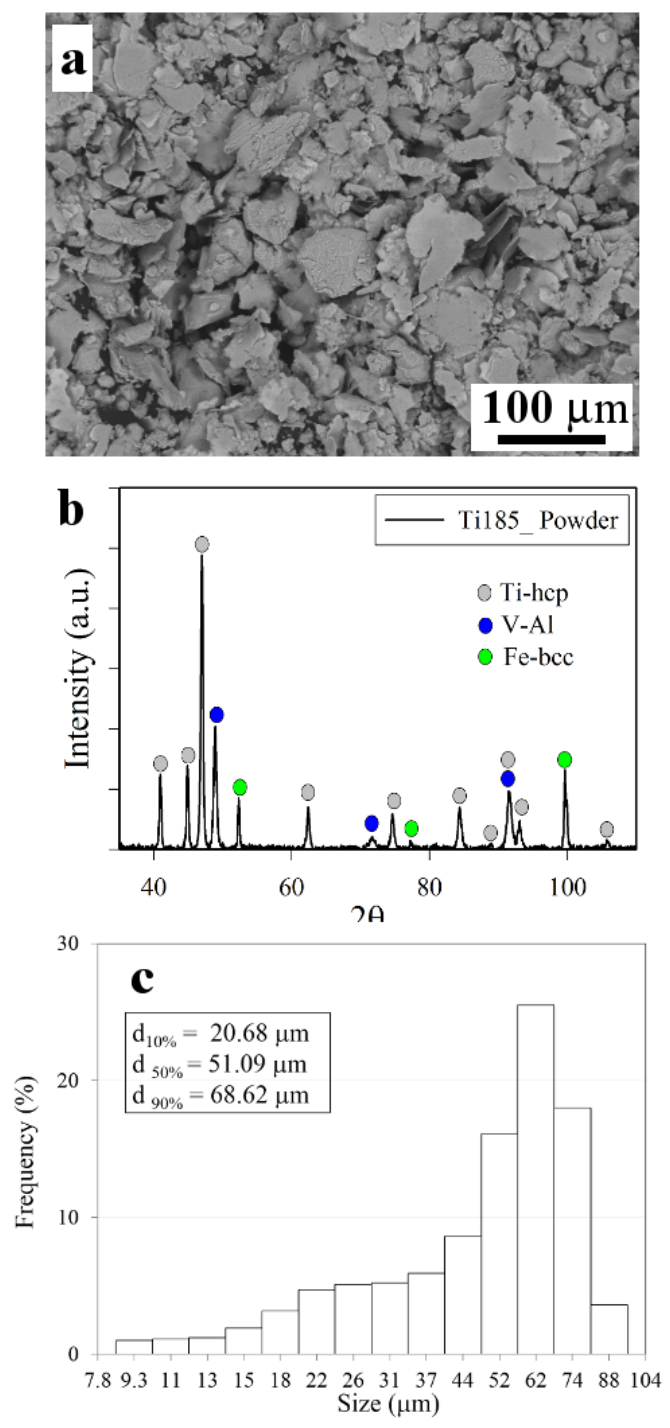

Figure 1: (a) SEM image of the Ti-185 powder used in this study, (b) XRD pattern of the as-built sample and (c) particle size distribution analysis.
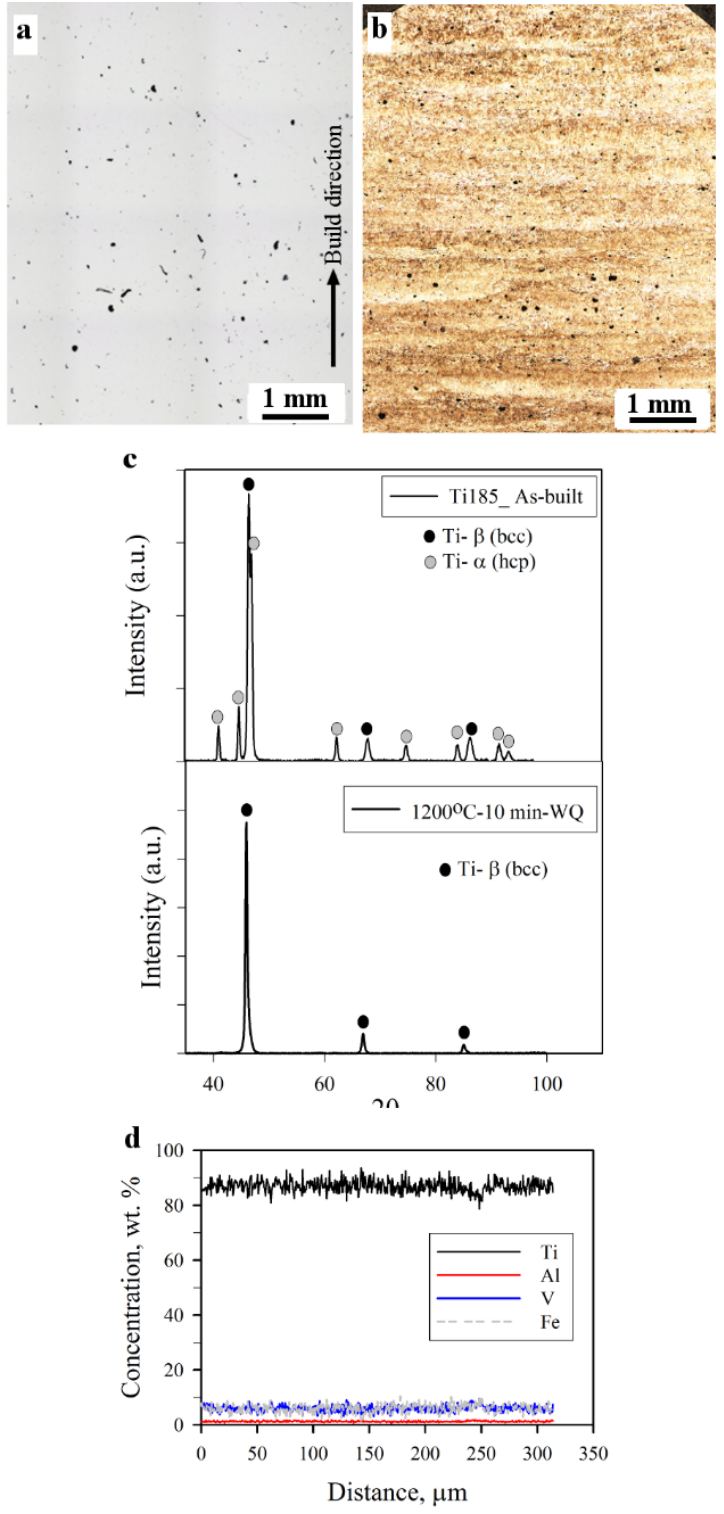

Figure 2: $(a, b)$ Optical micrographs of the asbuilt structure in the polished and etched conditions, (c) XRD pattern of the as-built structure and a sample subsequently heated to $1200{ }^{\circ} \mathrm{C}$ and then water quenched and (d) EDS line scan in the as-built sample in the build direction. (Note: the $\mathrm{Fe}$ and $\mathrm{V}$ lines overlap each other). 


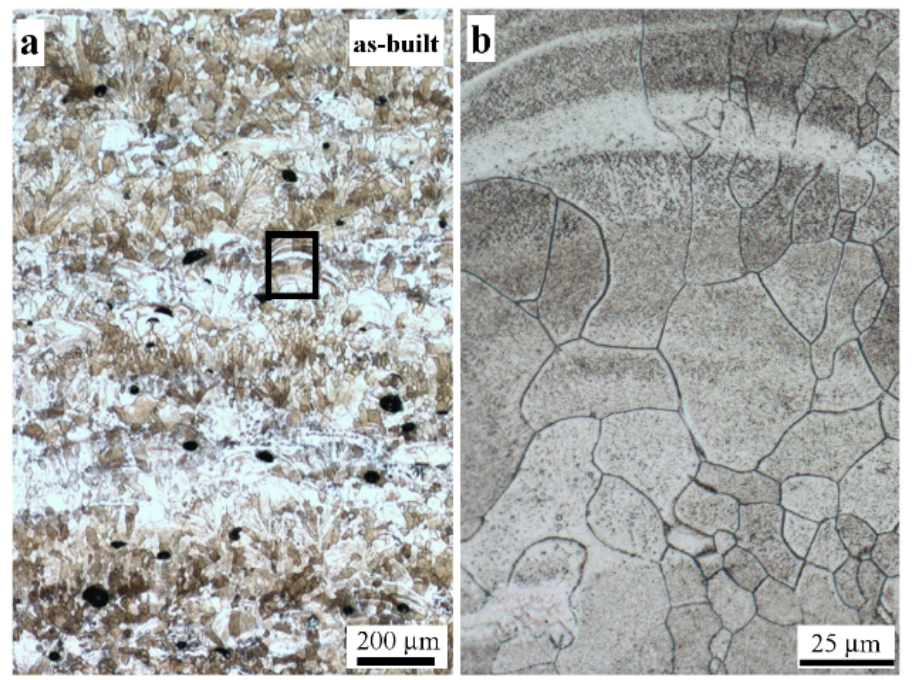

Figure 3: (a) Optical micrograph of the as-built structure; (b) a high-resolution image from the box in (a) showing inhomogeneous distribution of precipitates. The build direction is vertical.

The images provided in Figure 2 show that Ti-185 can be produced using SLM process to create a high-integrity structure, but what does the microstructure look like? In Figure 3, optical micrographs of the as-built Ti-185 structure are shown. Figure 3a shows a low-resolution optical image of the as-built sample; the grain size is rather uniform, with a mean value of $\sim 13 \mathrm{um}$, Figure 3b. The very fine $\beta$ grain structure produced by SLM is in sharp contrast to the large $\beta$ grains that form when $\beta$-Ti alloys are produced via casting [20,21], which then requires extensive thermomechanical post-processing for the refinement. Another interesting observation is the variations in contrast as can be seen along the build direction in Figure 3a. Some areas of the microstructure are brighter as compared to the surrounding matrix as highlighted in Figure $3 \mathrm{~b}$. To further investigate this observation, high resolution EBSD maps were obtained of the as-built microstructure. Figure 4a shows the EBSD band contrast map of the as-built sample depicting high angle gbs. At this resolution, only a few $\alpha$ phase particles can be seen. Figure $4 \mathrm{~b}$ shows a high-resolution EBSD image of the identified white square. As can be seen, the structure actually consists of a $\beta$ matrix in white with fine $\alpha$ phase films along the grain boundaries, as well as $\alpha$ 


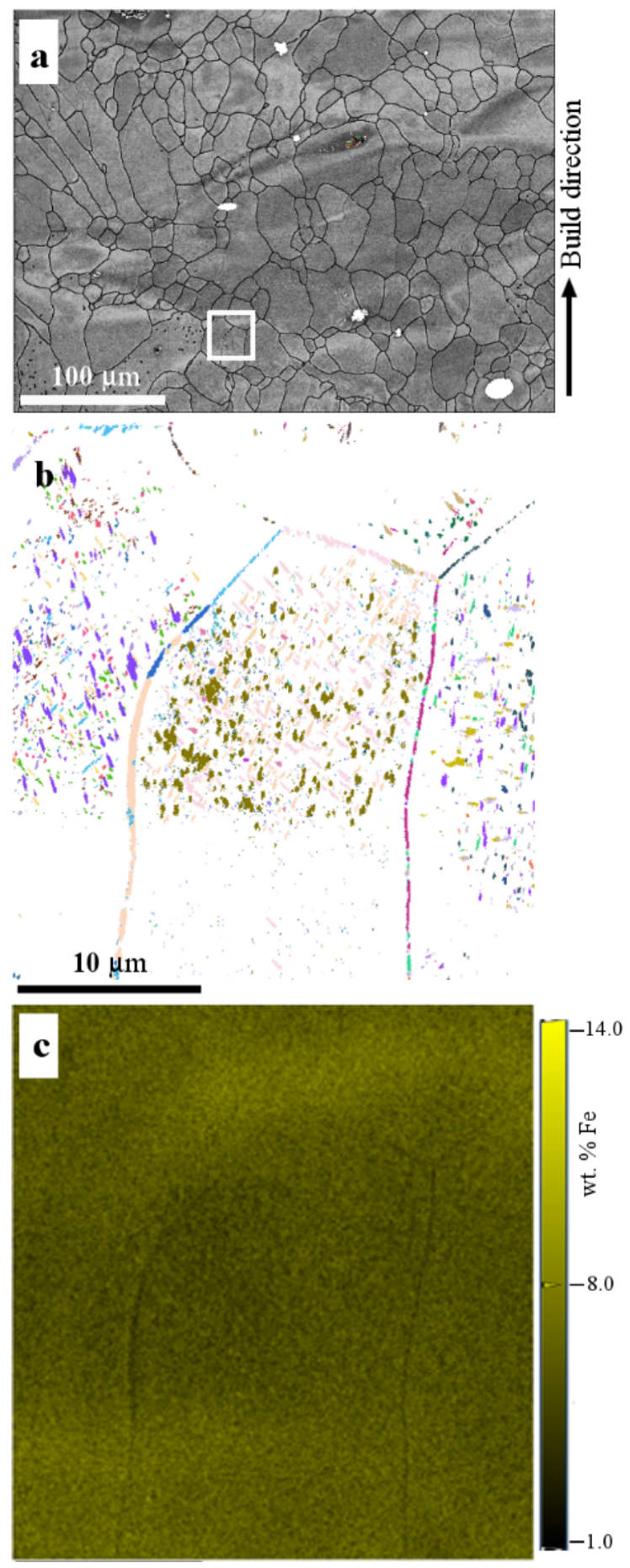

Figure 4: Band contrast image of the as-built structure with superimposed grain boundary map (white spots are un-indexed points and solid lines are high angle grain boundaries), (b) alpha phase map from the highlighted area in (a) (note: grain boundaries in beta ( $\beta$ ) phase matrix are decorated with primary alpha phase, and (c) corresponding iron $(\mathrm{Fe})$ map showing the partitioning of iron between alpha and beta $(\beta)$ region. 
precipitates within the grains. The interior $\alpha$ precipitates appear to have an orientation relationship with the $\beta$ matrix, suggesting that these precipitated from $\beta$ during cooling. An interesting observation from Figure $4 \mathrm{~b}$ is that it appears that the $\alpha$ phase is inhomogeneously distributed even within a single $\beta$ grain. It is hypothesized that this inhomogeneous distribution of $\alpha$ phases is responsible for the "white band" contrast seen in Figure 3b that appears on a repeating basis. The EDS elemental map of Fe, Figure 4c also show the inhomogeneous distribution of the $\alpha$ phases. Specifically, areas having limited $\alpha$ phase contain $8-11$ wt. \% Fe while areas with a higher density of the $\alpha$ phase contains 2-5 wt. \% Fe. This is consistent with Fe being an effective $\beta$ stabilizer. Thus, although there was no macro-segregation of alloying elements (Figure 2d), there is clearly local partitioning and segregation of alloying elements on a layer-by-layer basis during SLM, leading to an inhomogeneous distribution of the $\alpha$ phase within individual grains. Figure 5 shows a schematic of the thermal history experienced by a single layer of elemental Ti-185 powder during the SLM process. This schematic can be used to propose a mechanism for the inhomogeneous $\alpha$ phase formation seen in Figure 4. The powder first experiences melting and solidification, stage 1. During this process, the liquid transforms into the $\beta$-phase, as confirmed by Thermo-Calc [22]. Next, the layer is heat treated during deposition of the successive layers, stages 2 and 3 . If the temperature achieved during this in situ heat treatment exceeds the $\beta$-transus temperature, a fully $\beta$ - beta structure will develop. The XRD results presented in Figure $2 \mathrm{c}$ verify this hypothesis, as it shows that a sample heat treated at $1200{ }^{\circ} \mathrm{C}$ for 10 min followed by water quenching consists of fully $\beta$-phase structure. However, heat treatment will also take place below the $\beta$ - transus temperature as further layers are added to the build. In this case, the $\alpha$ phase can form at the boundaries as well as interior of the $\beta$-beta matrix, stage 3 . A higher oxygen content increases the $\beta$-transus temperature, thus expanding the range in which such the formation of the $\alpha$ phase can 
occur. Similar microstructures developed through in situ heat treatment during SLM have been reported for other titanium alloys $[19,23]$. Figure $6 \mathrm{a}$ is a bright field TEM image of the as-built sample. Analysis of the selected area diffraction pattern, Figure $6 \mathrm{~b}$, and dark field images, Figure 6c, confirm the presence of the $\alpha$ phase as well as a small fraction of $\omega$ phase. The $\alpha$ phase has a plate-like shape with an average length of $305 \mathrm{~nm}$ and a width of $\sim 55 \mathrm{~nm}$. The $\omega$ phase is very fine, $<50 \mathrm{~nm}$, and is located in contact with the $\alpha$ phase. This suggests nucleation of the $\alpha$ phase from the $\omega$ phase as reported in the literature [24,25]. The TEM image has also revealed the presence of a high dislocation density, Figure 6e, in the as-built sample. This is a common feature of AM material due to the high thermal stresses that develop during the fast cooling rates [26,27].

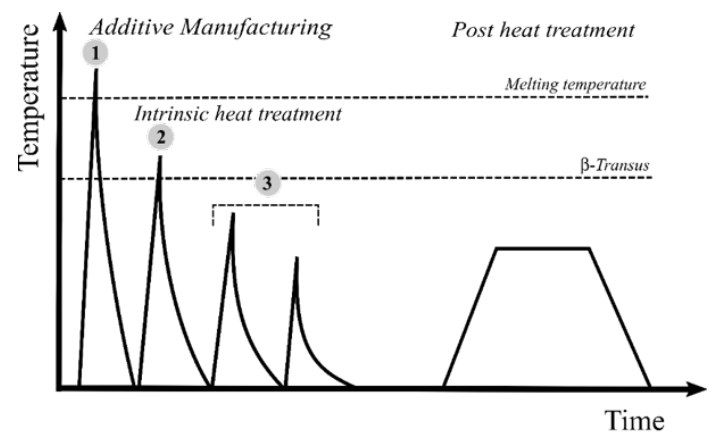

Figure 5: Schematic illustration of the temperature-time profile of the Ti-185 alloy experienced during the SLM process followed by a post heat treatment. For the Ti185 having $0.78 \mathrm{wt} . \% \mathrm{O}$, the equilibrium melting and the $\beta$-transus temperatures are $1650{ }^{\circ} \mathrm{C}$ and $980{ }^{\circ} \mathrm{C}$, respectively. Adopted from [28].
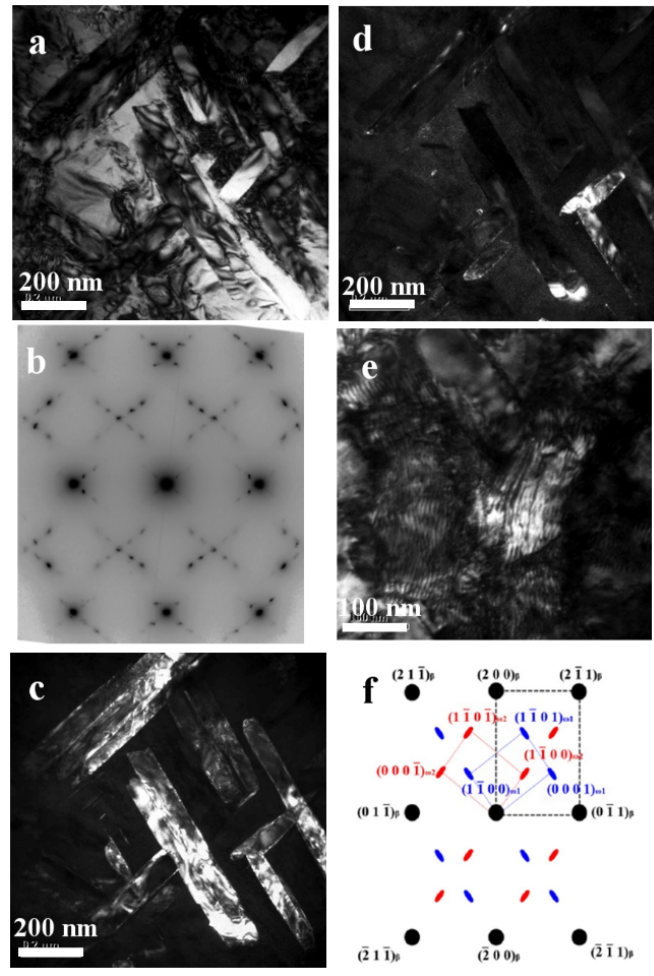

Figure 6: (a) Bright-field TEM image of the as-built sample; (b) diffraction pattern and (c), (d) dark field images of the $\alpha$ and $\omega$ phases; (e) dislocation structure within the $\beta$ matrix; (f) analysis of the diffraction pattern showing the $\alpha, \beta$, and $\omega$ spots. 


\subsection{Characterization of the heat-treated microstructure}

After the SLM processing, additional heat treatment can be introduced to further modify the microstructure, as sketched at the end of Figure 5. The aging treatment may change the morphology and distribution of $\alpha$ phase seen in Figure $4 \mathrm{~b}$ and/or lead to grain growth depending on applied temperature and its duration. Figure 7 shows the microstructure of the as-built sample aged at $800{ }^{\circ} \mathrm{C}$ and $960{ }^{\circ} \mathrm{C}$ for $1 \mathrm{hr}$ and $30 \mathrm{~min}$, respectively, followed by a water quench. At the lower heat treatment temperature, Figure 7a., a fine grain distribution is maintained as the grain boundaries are pinned by the $\alpha$ phase. A uniform distribution of $\alpha$ phase within the $\beta$ matrix is achieved, Figure $7 \mathrm{c}$. However, at $960^{\circ} \mathrm{C}$, the grains have grown larger, Figure $7 \mathrm{~b}$, as compared to the samples aged at $800{ }^{\circ} \mathrm{C}$. The process of $\alpha$ phase spheroidization has also taken place, Figure 7d. Based on the diffusivity of $\mathrm{Fe}$ in the $\beta$ phase [29], a diffusion distance of $16 \mu \mathrm{m}$ was calculated at $800{ }^{\circ} \mathrm{C}$ for $1 \mathrm{hr}$. This distance is comparable with the scale of the precipitate heterogeneity seen in Figure $3 b$, and explains the observed uniform distribution of the $\alpha$ phase.
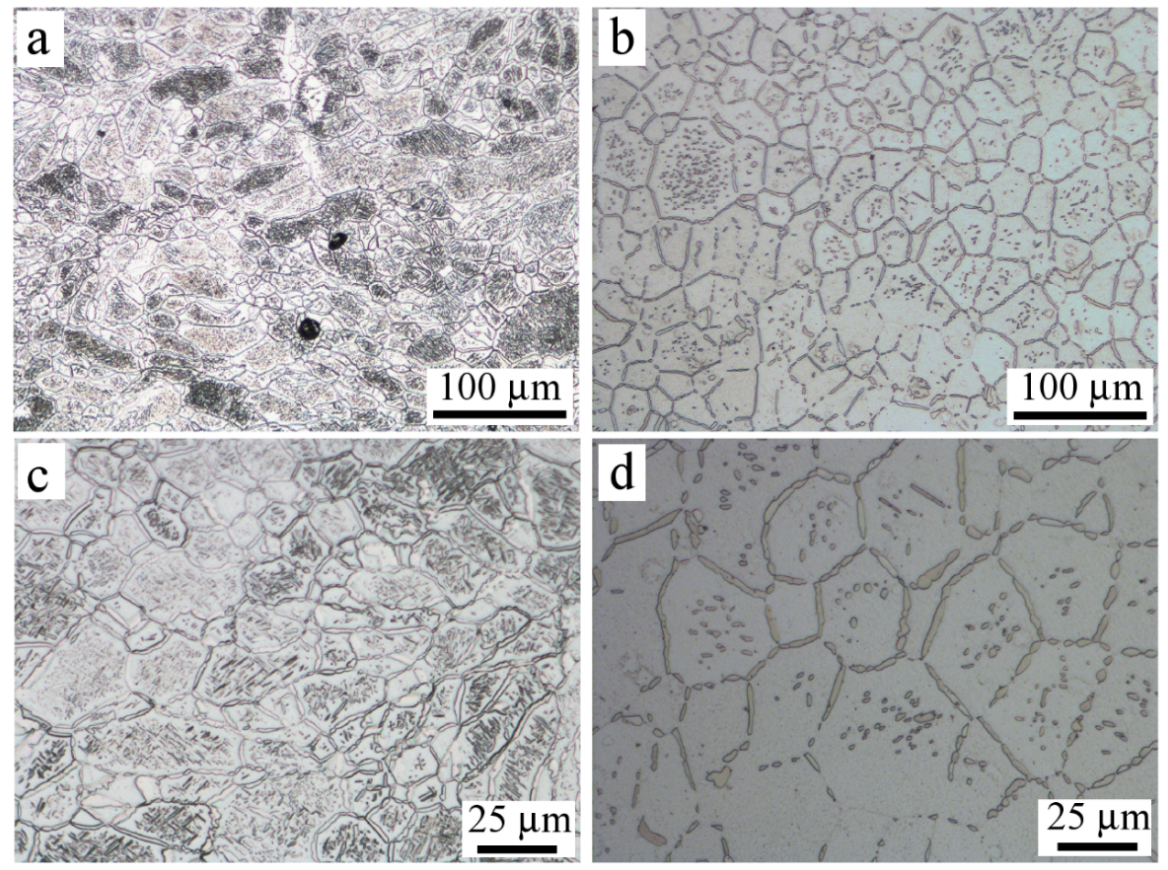

Figure 7: Evolution of the grain size and alpha precipitates during aging at (a, c) $800^{\circ} \mathrm{C}$ for $1 \mathrm{~h}$ and $(\mathrm{b}, \mathrm{d}) 960^{\circ} \mathrm{C}$ for $30 \mathrm{~min}$. Build direction is in vertical direction. 


\subsection{Mechanical Properties}

Figure 8 shows compression test results on the as-built sample as well as the sample heat treated at $960^{\circ} \mathrm{C}$ for $30 \mathrm{~min}$. As can be seen, the as-built material showed a very high compression strength, reaching $\sim 1.7 \mathrm{GPa}$ at a plastic strain of 0.1 prior to failure. The corresponding hardness was measured to be $\sim 470 \mathrm{HV}$. As a result of the heat treatment, both the compressive strength and strain to failure have increased, to $\sim 1.8 \mathrm{GPa}$ and 0.3 , respectively. The compression strength of both the SLM-built and heat treated Ti-185 alloy are seen to be significantly higher in comparison to the powder processed as-sintered Ti-185 alloy as well as the in situ heat treated Ti-5553 alloy developed through the SLM process, Table $2[8,21]$.

The excellent combination of high strength and plasticity in the as-built sample is achieved as a result of four main contributing factors: (1) the fine grain size of the as-built sample that strengthens via a Hall-Petch type relation [30, 31, 32]; (2) a high dislocation density present in AM-built structures that has been estimated to reach $10^{15} \mathrm{~m} / \mathrm{m}^{3}$ and coming close to values seen in heavily deformed metals [27], nano-scale alpha $(\alpha)$ phase distributed within the $\beta$-beta matrix that provide dispersion strengthening [4]; and (4) high oxygen content that hardens Ti via solid solution strengthening [33].In the heat treated sample, the modification of the alpha phase distribution without a significant change in the beta grain size is seen to provide an improved combination of strength and plasticity, the details of which require further investigation. Future work will also examine the effect of oxygen content; lowering the oxygen content (e.g. below 0.4 wt. \%) is expected to lead to further improvements in ductility and toughness. 


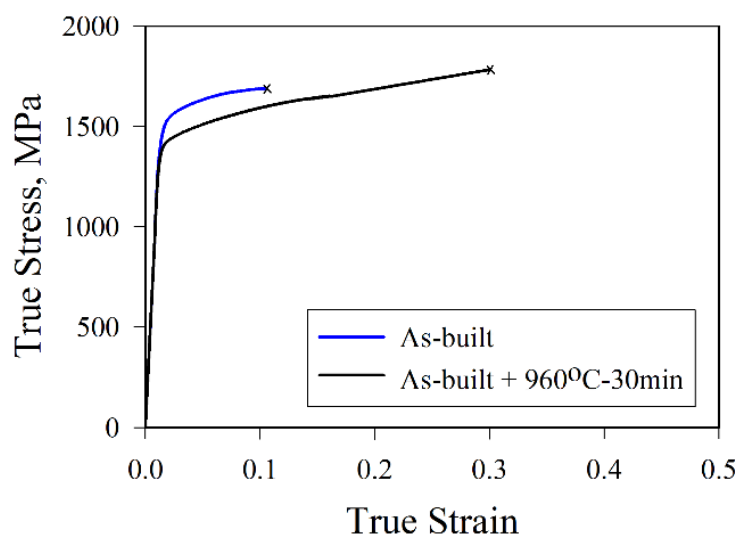

Figure 8: True compressive stress-strain curves of the as-built and heat treated $\left(960{ }^{\circ} \mathrm{C}-30 \mathrm{~min}\right)$ Ti-185 sample. Points of failure are identified by crosses.

Table 2: Compression mechanical properties of the (near) $\beta$-beta Ti alloys

\begin{tabular}{ccc|cc}
\hline \multirow{2}{*}{ Alloy } & \multicolumn{2}{c|}{ Compression. Strength, MPa } & \multicolumn{2}{c}{ Strain to failure } \\
\cline { 2 - 5 } & Eng. Stress & True Stress & Eng. Strain, \% & True Strain \\
\hline Ti-185-P/M*[21] & 1773 & - & $\sim 15$ & - \\
\hline Ti-185-AM (As-Built) & 1890 & 1696 & 11 & 0.11 \\
\hline Ti-185-AM (Heat treated) & 2380 & 1760 & 26 & 0.3 \\
\hline Ti-5553-AM $[8]$ & - & 1600 & 22 & - \\
\hline
\end{tabular}

*P/M: Powder metallurgy processed

\section{Conclusions}

An Fe-containing Ti alloy prone to embrittlement due to severe segregation during ingot casting, Ti-185, has been successfully produced by SLM. The combination of the small grains found in the as-built Ti-185 and the absence of these $\beta$ flecks provide strong metallurgical evidence that Ti-185 is a promising material for SLM. A remarkable combination of strength and plasticity is achieved as a result of a very fine-grained structure, nano-scale alpha phase distributed within the beta $(\beta)$ matrix, high dislocation density as well as high oxygen content. This process can open a new avenue for developing a new family of Fe-containing titanium alloys for additive manufacturing. 


\section{Acknowledgements}

We would like to acknowledge Mr. Peng Shen from Stackpole International, Mississauga, for the help on powder characterization, Mr. Yuxiang Wu from Monash University for Thermo-Calc calculations, and Dr. Lukas Bichler from The University of British Columbia for the Archimedes test. Access to the Canadian Centre for Electron Microscopy, a national facility funded by NSERC and McMaster University is gratefully acknowledged. Funding support provided by the Natural Science and Engineering Council of Canada is gratefully acknowledged

\section{References}

[1] Boyer RR, Briggs RD. The Use of $\beta$ Titanium Alloys in the Aerospace Industry. J. of Materi Eng and Perform. 2013; 22: 2916-2920.

[2] Mitchell A, Kawakami A, Cockcroft SL. Beta Fleck and Segregation in Titanium Alloy Ingots. High Temperature Materials and Processes. 2006; 25:337-349.

[3] Mitchell A, Kawakami A, Cockcroft SL. Segregation in Titanium Alloy Ingots. High Temperature Materials and Processes. 2007; 26: 59-78.

[4] Joshi VV, Lavender C, Moxon V, et al. Development of Ti-6Al-4V and Ti-1Al-8V-5Fe Alloys Using Low-Cost TiH2 Powder Feedstock. J. of Materi Eng and Perform. 2012; 22: 995-1003.

[5] Vander Voort GF, Metallography and microstructure of titanium and its microstructures, Metals Handbook Desk Edition, Second Edition, ASM International, 1998, in ASM Handbooks Online, http://www.asmmaterials.info ASM International, 2004.

[6] Devaraj A, Joshi VV, Srivastava A, et al. A low-cost hierarchical nanostructured beta-titanium alloy with high strength. Nat Commun. 2016;7:11176.

[7] H. Schwab, F. Palm, U. Kühn, J. Eckert, Microstructure and mechanical properties of the near-beta titanium alloy Ti-5553 processed by selective laser melting, Materials \& Design. 105 (2016) 75-80. doi:10.1016/j.matdes.2016.04.103.

[8] H. Schwab, M. Bönisch, L. Giebeler, T. Gustmann, J. Eckert, U. Kühn, Processing of Ti-5553 with improved mechanical properties via an in-situ heat treatment combining selective laser melting and substrate plate heating, Materials \& Design. 130 (2017) 83-89. doi:10.1016/j.matdes.2017.05.010.

[9] Y.J. Liu, S.J. Li, H.L. Wang, W.T. Hou, Y.L. Hao, R. Yang, T.B. Sercombe, L.C. Zhang, Microstructure, defects and mechanical behavior of beta-type titanium porous structures manufactured by electron beam melting and selective laser melting, Acta Materialia. 113 (2016) 56-67. doi:10.1016/j.actamat.2016.04.029.

[10] Y.J. Liu, H.L. Wang, S.J. Li, S.G. Wang, W.J. Wang, W.T. Hou, Y.L. Hao, R. Yang, L.C. Zhang, Compressive and fatigue behavior of beta-type titanium porous structures fabricated by electron beam melting, Acta Materialia. 126 (2017) 58-66. doi:10.1016/j.actamat.2016.12.052.

[11] L.C. Zhang, D. Klemm, J. Eckert, Y.L. Hao, T.B. Sercombe, Manufacture by selective laser melting and mechanical behavior of a biomedical Ti-24Nb-4Zr-8Sn alloy, Scripta Materialia. 65 (2011) 21-24. doi:10.1016/j.scriptamat.2011.03.024. 
[12] L.-C. Zhang, H. Attar, Selective Laser Melting of Titanium Alloys and Titanium Matrix Composites for Biomedical Applications: A Review, Adv. Eng. Mater. 18 (2016) 463-475.

doi:10.1002/adem.201500419.

[13] Frazier WE. Metal Additive Manufacturing: A Review. J. of Materi Eng and Perform. 2014; 23:19171928.

[14] Eylon D, Froes FH, Titanium powder metallurgy products, Metals Handbook Desk Edition, Second Edition, ASM International, 1998, in ASM Handbooks Online, http://www.asmmaterials.info ASM International, 2004.

[15] Y. Hu, J. Li, Selective laser alloying of elemental titanium and boron powder: Thermal models and experiment verification, Journal of Materials Processing Technology. 249 (2017) 426-432.

doi:10.1016/j.jmatprotec.2017.06.029.

[16] S. Shiva, I.A. Palani, S.K. Mishra, C.P. Paul, L.M. Kukreja, Investigations on the influence of composition in the development of $\mathrm{Ni}$-Ti shape memory alloy using laser based additive manufacturing, Optics \& Laser Technology. 69 (2015) 44-51. doi:10.1016/j.optlastec.2014.12.014.

[17] ASTM B213 - 17 Standard Test Methods for Flow Rate of Metal Powders Using the Hall Flowmeter Funnel.

[18] ASTM B213 - 17 Standard Test Method for Apparent Density of Free-Flowing Metal Powders Using the Hall Flowmeter Funnel

[19] Xu W, Lui EW, Pateras A, et al. In situ tailoring microstructure in additively manufactured Ti-6Al4V for superior mechanical performance. Acta Materialia. 2017; 125: 390-400.

[20] Eylon D., Newman JR, Thorne JK, Metals Handbook, vol. 2, ASM International, Materials Park, OH (1991), p. 634.

[21] Y. Zhang, C. Wang, Y. Zhang, P. Cheng, Y. Wei, S. Xiao, Y. Chen, Fabrication of low-cost Ti-1Al$8 \mathrm{~V}-5 \mathrm{Fe}$ by powder metallurgy with $\mathrm{TiH} 2$ and FeV80 alloy, Materials and Manufacturing Processes. 32

(2017) 1869-1873. doi:10.1080/10426914.2017.1303163.

[22] Thermo-Calc Software TTTI3 Titanium/Ti-alloys database, version 3.

[23]Xu W, Brandt M, Sun S, et al. Additive manufacturing of strong and ductile Ti-6Al-4V by selective laser melting via in situ martensite decomposition. Acta Materialia. 2015;85:74-84.

[24] Li T, Kent D, Sha G, et al. The role of $\omega$ in the precipitation of $\alpha$ in near- $\beta$ Ti alloys. Scripta Materialia. 2016; 117: 92-95.

[25] Li T, Kent D, Sha G, et al. The mechanism of $\omega$-assisted $\alpha$ phase formation in near $\beta$-Ti alloys. Scripta Materialia. 2015; 104: 75-78.

[26] Divya VD, Muñoz-Moreno R, Messé OMDM, et al. Microstructure of SLM CM247LC nickel-based superalloy and its evolution through heat treatment. Materials Characterization. 2016; 114: 62-74.

[27] S. Gorsse, C. Hutchinson, M. Gouné, R. Banerjee, Sci \& Techn Adv Materials 18 (2017) 584-610.

[28] E.A. Jägle, Z. Sheng, L. Wu, L. Lu, J. Risse, A. Weisheit, D. Raabe, Precipitation Reactions in AgeHardenable Alloys During Laser Additive Manufacturing, JOM; New York. 68 (2016) 943-949. doi:http://dx.doi.org.ezproxy.library.ubc.ca/10.1007/s11837-015-1764-2.

[29] Nakajima H, Ohshida S, Nonaka K. Diffusion of iron in $\beta$ Ti-Fe alloys. Scr. Mat. 1996; 34:949-953.

[30] K. Okazaki, H. Conrad, Effects of interstitial content and grain size on the strength of titanium at low temperatures, Acta Metallurgica. 21 (1973) 1117-1129. doi:10.1016/0001-6160(73)90028-X.

[31] A. Bhattacharjee, P. Ghosal, T.K. Nandy, S.V. Kamat, A.K. Gogia, S. Bhargava, Effect of grain size on the tensile behaviour and fracture toughness of Ti-10V-4.5Fe-3Al beta titanium alloy, Trans Indian Inst Met. 61 (2008) 399-405. doi:10.1007/s12666-008-0071-9.

[32] A. Bhattacharjee, V.K. Varma, S.V. Kamat, A.K. Gogia, S. Bhargava, Influence of $\beta$ grain size on tensile behavior and ductile fracture toughness of titanium alloy Ti-10V-2Fe-3Al, Metall and Mat Trans A. 37 (2006) 1423-1433. doi:10.1007/s11661-006-0087-x.

[33] Z. Liu, G. Welsch, Effects of oxygen and heat treatment on the mechanical properties of alpha and beta titanium alloys, MTA. 19 (1988) 527-542. doi:10.1007/BF02649267. 